Provided for non-commercial research and education use. Not for reproduction, distribution or commercial use.

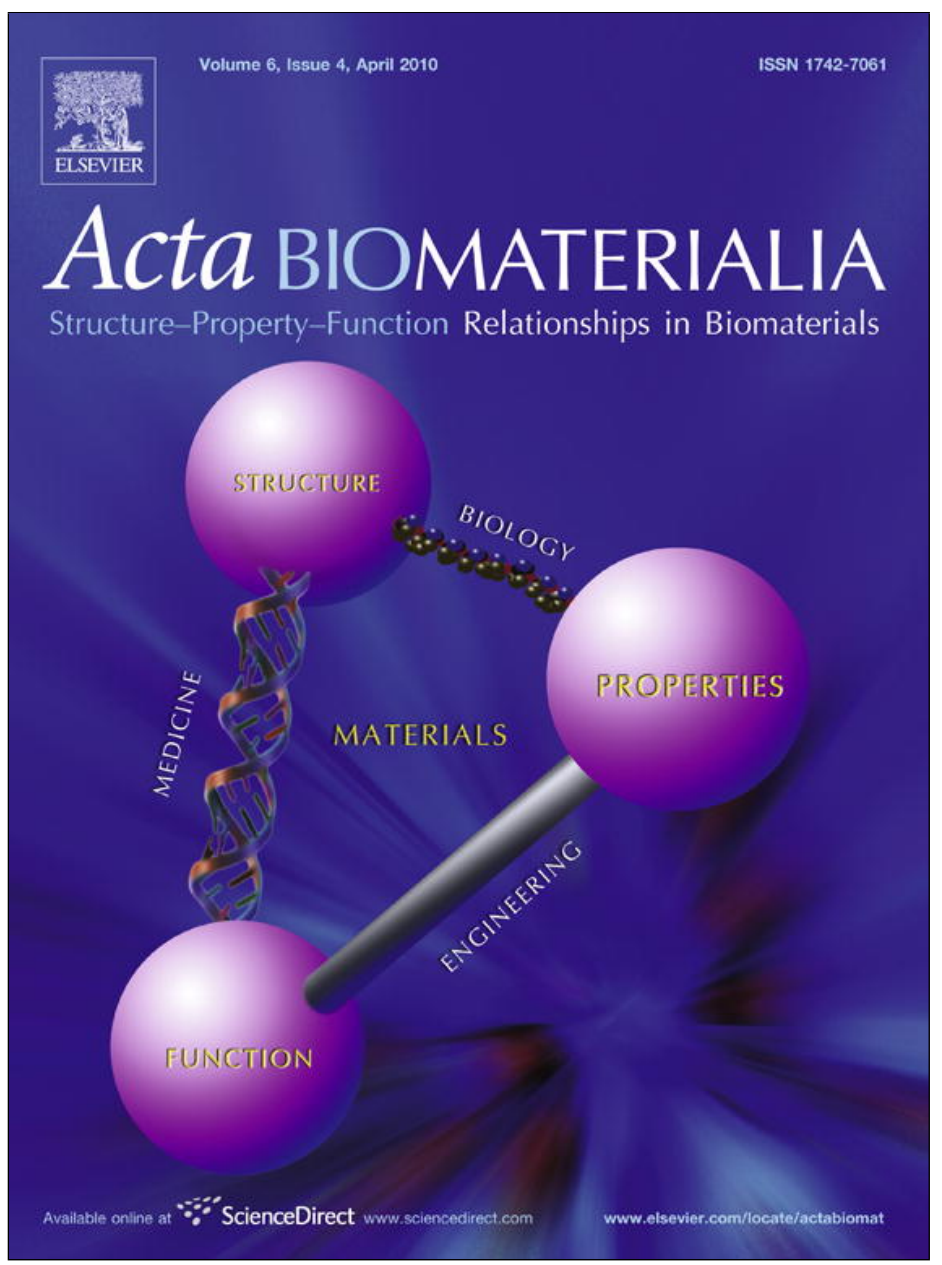

This article appeared in a journal published by Elsevier. The attached copy is furnished to the author for internal non-commercial research and education use, including for instruction at the authors institution and sharing with colleagues.

Other uses, including reproduction and distribution, or selling or licensing copies, or posting to personal, institutional or third party websites are prohibited.

In most cases authors are permitted to post their version of the article (e.g. in Word or Tex form) to their personal website or institutional repository. Authors requiring further information regarding Elsevier's archiving and manuscript policies are encouraged to visit:

http://www.elsevier.com/copyright 


\title{
Multiscale three-dimensional scaffolds for soft tissue engineering via multimodal electrospinning
}

\author{
Sherif Soliman ${ }^{\mathrm{a}, 1}$, Stefania Pagliari ${ }^{\mathrm{b}, 1}$, Antonio Rinaldi ${ }^{\mathrm{a}, 1}$, Giancarlo Forte ${ }^{\mathrm{b}}$, Roberta Fiaccavento ${ }^{\mathrm{b}}$, \\ Francesca Pagliari ${ }^{b}$, Ornella Franzese ${ }^{c}$, Marilena Minieri ${ }^{b}$, Paolo Di Nardo ${ }^{b}$, Silvia Licoccia ${ }^{a}$, \\ Enrico Traversa ${ }^{\mathrm{a}, \mathrm{d}, *}$ \\ ${ }^{a}$ NAST Centre and Department of Chemical Science and Technology, University of Rome Tor Vergata, 00133 Rome, Italy \\ ${ }^{\mathrm{b}}$ Department of Internal Medicine, University of Rome Tor Vergata, 00133 Rome, Italy \\ ${ }^{\mathrm{c}}$ Department of Neuroscience, University of Rome Tor Vergata, 00133 Rome, Italy \\ ${ }^{\mathrm{d}}$ International Research Center for Materials Nanoarchitectonics (MANA), National Institute for Materials Science (NIMS), 1-1 Namiki, Tsukuba, 305-0044 Ibaraki, Japan
}

\section{A R T I C L E I N F O}

\section{Article history:}

Received 17 June 2009

Received in revised form 28 October 2009

Accepted 29 October 2009

Available online 1 November 2009

\section{Keywords:}

Electrospinning

Multiscale scaffold

Nanofibers

Microfibers

Soft tissue engineering

\begin{abstract}
A B S T R A C T
A novel (scalable) electrospinning process was developed to fabricate bio-inspired multiscale threedimensional scaffolds endowed with a controlled multimodal distribution of fiber diameters and geared towards soft tissue engineering. The resulting materials finely mingle nano- and microscale fibers together, rather than simply juxtaposing them, as is commonly found in the literature. A detailed proof of concept study was conducted on a simpler bimodal poly( $\varepsilon$-caprolactone) (PCL) scaffold with modes of fiber distribution at $600 \mathrm{~nm}$ and $3.3 \mu \mathrm{m}$. Three conventional unimodal scaffolds with mean diameters of $300 \mathrm{~nm}$ and 2.6 and $5.2 \mu \mathrm{m}$, respectively, were used as controls to evaluate the new materials. Characterization of the microstructure (i.e. porosity, fiber distribution and pore structure) and mechanical properties (i.e. stiffness, strength and failure mode) indicated that the multimodal scaffold had superior mechanical properties (Young's modulus $\sim 40 \mathrm{MPa}$ and strength $\sim 1 \mathrm{MPa}$ ) in comparison with the controls, despite the large porosity ( $\sim 90 \%$ on average). A biological assessment was conducted with bone marrow stromal cell type (mesenchymal stem cells, mTERT-MSCs). While the new material compared favorably with the controls with respect to cell viability (on the outer surface), it outperformed them in terms of cell colonization within the scaffold. The latter result, which could neither be practically achieved in the controls nor expected based on current models of pore size distribution, demonstrated the greater openness of the pore structure of the bimodal material, which remarkably did not come at the expense of its mechanical properties. Furthermore, nanofibers were seen to form a nanoweb bridging across neighboring microfibers, which boosted cell motility and survival. Lastly, standard adipogenic and osteogenic differentiation tests served to demonstrate that the new scaffold did not hinder the multilineage potential of stem cells.
\end{abstract}

(c) 2009 Acta Materialia Inc. Published by Elsevier Ltd. All rights reserved.

\section{Introduction}

The design and fabrication of biocompatible scaffolds are the core tasks of tissue engineering from a materials science perspective [1]. An effective scaffold should provide selected cell cultures with a suitable substrate for adhesion and proliferation and, if necessary, drive stem cell differentiation into a targeted implantable tissue. After some advances and relatively successful clinical applications

\footnotetext{
* Corresponding author. Address: International Research Center for Materials Nanoarchitectonics (MANA), National Institute for Materials Science (NIMS), 1-1 Namiki, Tsukuba, 305-0044 Ibaraki, Japan. Tel.: +8129860 4896; fax: +8129860 4706.

E-mail addresses: traversa@uniroma2.it, traversa.enrico@nims.go.jp (E. Traversa).

1 These authors contributed equally to this work.
}

for hard tissues over the past decade [2,3], much of the effort is now being directed at soft tissue reconstruction. Engineering twodimensional (2D) soft tissues (e.g. cornea [4] and skin [5]), and complex three-dimensional (3D) tissues (e.g. cardiac, muscular and neural) is a far more challenging task. Materials scientists are currently tackling this problem by investigating bio-inspired scaffolds that seek to reproduce the cell environment, i.e. the extra cellular matrix (ECM) of the native tissue [6,7]. The complex, multiscale nature of ECM in such tissues, which consists of an intricate network of structural and functional proteins arranged into a fibrous matrix, renders scaffold design a formidable task. A bio-inspired cell-scaffold interface must necessarily meet a variety of demanding and coupled requirements, such as biocompatibility and biodegradability of the materials, chemo-mechanical properties [8,9] and morphological characteristics [6,7], all at different length scales. 
Amongst the manufacturing techniques available at present electrospinning allows the fabrication of distinctive scaffolds with nanoscale "filaments" as in the ECM [10-13]. Electrospun scaffolds consist of 3D, non-woven, highly porous mats, resembling an intricate forest of fibers randomly overlaid on each other. These fibers are exceedingly long (km range) compared with their diameters $(\omega)$, which usually follow a unimodal statistical distribution. The mean and spread of such distributions can be controlled and tweaked via process parameters over a wide range, from a few nanometers to hundreds of microns [10-23]. The fiber diameter $\omega$ is regarded as the prime controllable design parameter to steer scaffold performance in terms of cell response. Reportedly, nanoscale fibers, in the absence of beads, were found to accelerate and improve cell adhesion and proliferation in the presence of growth factors with respect to the microscale counterpart - partly owing to the higher specific surface area providing a kinetic boost $[18,21]$. Nanofibers also appeared to sustain growth factor-induced stem cell differentiation $[14,15,17,22,23]$. However, dense nanoscale networks are not optimal, as they tend to block cell migration through the thickness and are outperformed by microscale fibers in terms of cell ingrowth and viability [20]. In fact, after homogeneous cell delivery onto the surface (for seeding details see $[2,22,24,25])$ only the presence of interconnected pores, large enough compared with the dimension of seeded cells, renders the substrate permeable to cells and permits tissue formation [26]. For instance, pore sizes of $100-350 \mu \mathrm{m}$, along with porosities of greater than $90 \%$, are recommended for bone regeneration $[14,27]$. Besides cell migration, both porosity and pore size distribution are also crucial to perfusion of cell metabolites and catabolites through the scaffold and ECM formation [28]. In general, though, the pore size distribution is not an independent parameter, but is controlled indirectly through the selection of $\omega$. Recently, Eichhorn and Sampson $[29,30]$ proposed a statistical model that provides a theoretical estimate for the pore size distribution from a knowledge of the $\omega$ distribution (under some restrictions and for a unimodal fiber diameter distribution). Such a model predicts an increase in pore size with increasing average fiber diameter at fixed porosity, in agreement with previous experiments $[19,20,29]$. Hence, in its simplest form the design problem for a unimodal electrospun scaffold may be reduced to selection of the proper fiber distribution to deliver the optimal trade-off between sufficiently large pores and as small as possible fibers [20,31] However, for the general case of a 3D complex tissue the design problem is normally more complicated and must account for additional aspects, such as the need to achieve simultaneous vascularization of the engineered tissue $[6,7,15,17]$. To this end, one single scaffold ought to be capable of accommodating several cell populations seeded at one time, each having specific requirements in terms of fiber width and pore size $[22,23]$. This explains the pursuit for more advanced multiscale electrospun scaffolds. While some researchers have focused on unimodal fiber distributions spanning both the nanoscale and the microscale [21], others have begun to look for scaffolds featuring multimodal fiber distributions obtained by the combination of two or more fiber populations [16-19]. To date, this has typically been achieved by spinning microfibers and nanofibers alternately in a sequential fashion, to fabricate a layered composite that would inherit the advantages of both length scales and show enhanced cell functionality. Encouraging results were obtained. For example, cell motility and spreading could be significantly improved by adding a diluted network of $500 \mathrm{~nm}$ nanofibers over a dense substrate scaffold of bulky $160 \mu \mathrm{m}$ microfibers, where the nanoweb provided cells with a means to bridge across microfibers that were far apart and colonize the entire scaffold $[16,17]$. Similar observations were confirmed with thinner $5 \mu \mathrm{m}$ microfibers [19], highlighting that rate and depth of cell infiltration decreased with thickening of the nanofi- brous layer. In contrast, dense, thick layers may serve to intentionally block cell migration and subdivide the stack into separate compartments for diverse cell seeding of the scaffold [20]. In terms of fabrication, such multilayered architectures have been the result of a multi-step manufacturing process, in which standard electrospinning was used discontinuously in a step-wise fashion, either to spin all layers or just the nanoscale fibers, in combination with other techniques for the microscale fibers (e.g. the fiber bonding technique [16]).

In this context we present a novel multimodal architecture where the fiber distributions are not simply juxtaposed, but finely intermixed into a single, truly multimodal layer. This objective was achieved via a single step process (reducing the throughput time) using slightly modified electrospinning equipment. The new strategy is scalable and may be used alone or as part of a multilayer, multi-step design. A proof of concept study was conducted to demonstrate the feasibility of the method on a simple bimodal fiber mesh by mixing together two parent distributions of fibers one order of magnitude apart in average value $\langle\omega\rangle$ (i.e. $600 \mathrm{~nm}$ and $3.3 \mu \mathrm{m}$ ). That scenario was found to be more interesting and challenging than mingling together fibers more markedly different in size and with larger pore sizes available, as done by Santos et al [17]. The bimodal scaffold was compared with conventional electrospun scaffolds with mean diameters of $300 \mathrm{~nm}$ and 2.6 and $5.2 \mu \mathrm{m}$ to assess the materials and biological performance. The latter was assessed using a bone marrow stromal cell type (mTERTMSCs), determining viability, migration through the scaffold and differentiation towards adipogenic and osteogenic tissues. The selected base material for these experiments was poly( $\varepsilon$-caprolactone) (PCL).

\section{Materials and methods}

\subsection{Standard and mixing electrospinning apparatuses}

PCL was used due to its biocompatibility, capability of supporting many cell types [22], widespread usage, low cost, slow degradation rate and good mechanical properties [21,32]. Non-woven unimodal scaffolds made of PCL were electrospun using standard apparatus [11], depicted schematically in Fig. 1A. Commercial PCL polymer of density $\rho_{\mathrm{PCL}}=1.145 \mathrm{~g} \mathrm{ml}^{-1}$ was used (molecular weight 80,000 , Sigma, St. Louis, MO) throughout this study. The set-up consisted of a programmable pump (Model R100-E, Razel Scientific Instruments) interfaced with a computer and attached to a syringe with a blunt ended needle connected to a positive voltage supply (EN 61010-1, Glassman High Voltage Inc.). The polymer solution was delivered to a stainless steel grounded collecting plate. An auxiliary ring electrode made of copper was used to better control the spinning jet and the deposition area.

A series of PCL solutions were prepared of different polymer concentrations and these were electrospun under different process parameters to determine the optimal conditions to obtain reproducible nano- and microfibers. The processing parameters used to make the three control scaffolds reported in Table 1 ensured reproducible preparation of such matrices for $\langle\omega\rangle$ equal to 5.2 and $2.6 \mu \mathrm{m}$ and $300 \mathrm{~nm}$, respectively. The average fiber size $\langle\omega\rangle$ was found to largely depend on the solution viscosity (a thorough study of the electrospinning process parameters and their optimization is outside the scope of this article and will be discussed in a separate paper).

A second custom set-up, shown in Fig. 1B, was developed to accomplish the mixing strategy. Two different PCL polymer solutions, of different concentrations, were electrospun simultaneously from two parallel syringes that were actuated independently by individual pumps, under the conditions listed in Table 1, to form 


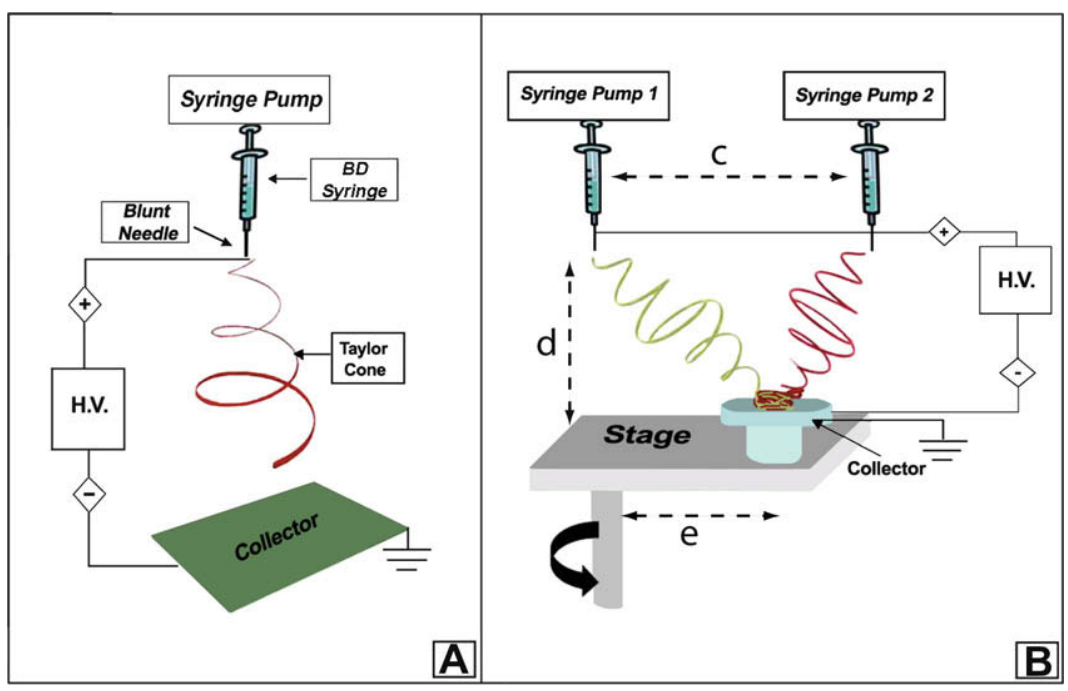

Fig. 1. Schematic representation of the standard ES experimental set-up (A) and of the modified version with two parallel syringes and actuated collector target for fabricating mixed fiber meshes (B). The set-up geometry is fully determined by the inter-axes distance between the mandrel and collector $e=8 \mathrm{~cm}$, the needle tip to collector plate distance $d=18-25 \mathrm{~cm}$ and the inter-axes distance between syringes $c=10 \mathrm{~cm}$ (actually placed symmetrically about the mandrel axis).

Table 1

Electrospinning process conditions and $\langle\omega\rangle$ distribution of the four types of scaffolds.

\begin{tabular}{|c|c|c|c|c|c|c|c|}
\hline Scaffold type & $\begin{array}{l}\text { Mean fiber diameter } \\
\langle\omega\rangle \pm \text { RMS }(\mu \mathrm{m})\end{array}$ & Solvent type & Concentration (wt.\%) & Collector distance $(\mathrm{cm})$ & Voltage (kV) & Flow rate $\left(\mathrm{ml} \mathrm{h}^{-1}\right)$ & Needle gauge \\
\hline Control 1 & $5.2 \pm 1.9$ & $\mathrm{CHCL}_{3} /$ methanol 7:1 & 15 & 30 & 12 & 4 & 18 \\
\hline Control 2 & $2.6 \pm 0.5$ & $\mathrm{CHCL}_{3} /$ methanol 6:1 & 10 & 10 & 12 & 6 & 18 \\
\hline Control 3 & $0.3 \pm 0.2$ & $\mathrm{CHCL}_{3} /$ methanol 3:1 & 8 & 30 & 20 & 4 & 23 \\
\hline \multirow[t]{2}{*}{ MIX (bimodal) } & $0.6 \pm 0.3$ & $\mathrm{CHCL}_{3} /$ methanol 3:1 & 7 & 20 & 15 & 4.5 & 19 \\
\hline & $3.3 \pm 1.0$ & $\mathrm{CHCL}_{3} /$ methanol 6:1 & 13 & 20 & 15 & 7.5 & 22 \\
\hline
\end{tabular}

the desired mesh of nano- and microfibers. Such a two channel setup allowed us to separately and broadly tune the nano- and microfibers, both in terms of their mean diameters $\langle\omega\rangle$ and relative percentages in the mix, by varying either one independently, as long as spinning remained stable. The two types of fibers were collected on a target set in rotation such that it alternately passed underneath each of the two syringes and collected proportionally more fibers from the closer needle at each instant. This was achieved by mounting the target eccentrically on a custom stage (inset in Fig. 1B) actuated by a high speed step motor at an optimal rotation rate of $30 \mathrm{rpm}$.

All four scaffold materials in Table 1 were arbitrarily spun to $100-200 \mu \mathrm{m}$ thickness (as measured case by case with a digital micrometer with a precision of $1 \mu \mathrm{m}$ ) by modulating electrospinning duration. Unless specified otherwise, all samples for materials and biological characterization consisted of disks $20 \mathrm{~mm}$ in diameter die punched from larger sheets.

\subsection{SEM characterization and fiber diameter measurements}

Scanning electron microscopy (SEM) was used to measure the fiber diameter distribution. Scaffolds were sputter coated with gold and observed using a field emission gun SEM (FEG-SEM) (LEO 35, Germany) at an accelerating voltage of $8 \mathrm{keV}$ to limit electron damage. The means and root mean square (r.m.s.) errors for each sample of the fiber populations reported in Table 1 were computed over a set of not less than 30 measures taken at random locations along the fibers observed in top view SEM micrographs at $5000 \times$ magnification. SEM micrographs of cross-sections of the scaffolds were also collected to evaluate the quality of nano- and microfibers mingling in the MIX scaffold and any gradient in thickness be- tween the top and bottom surfaces. For tensile testing purposes cross-sections were also examined to determine the planar solid fraction (SF) associated with PCL (determined as the ratio of the sum of all cross-sectional areas of cut fibers to the overall micrograph area - performed using Matlab ${ }^{\circledR}$, as described below). Cross-sectioning was performed by first dipping samples in liquid nitrogen, to induce brittleness, and then bending them until rupture with tweezers. At least five samples per scaffold type were considered for reproducibility in all SEM characterizations.

\subsection{Porosity measurements}

The scaffold porosity $(\varepsilon)$ was measured in three different ways for comparison, as its determination is non-trivial and method sensitive. The first consisted of a liquid intrusion procedure. Scaffolds were weighed prior to immersion in ethanol (intruding liquid of density $\rho_{\mathrm{EtOH}}=0.789 \mathrm{~g} \mathrm{ml}^{-1}$ ), left overnight on a shaker table to allow diffusion of ethanol into the void volume, blotted with a Kimwipe and reweighed. The porosity was calculated as $\varepsilon=V_{\mathrm{EtOH}} /\left(V_{\mathrm{EtOH}}+V_{\mathrm{PCL}}\right)$ by dividing the volume $V_{\mathrm{EtOH}}$ of the intruded ethanol (i.e. the ratio between the observed mass change after intrusion and $\rho_{\text {EtOH }}$ ) by the total volume after intrusion (equaling the sum of $V_{\mathrm{EtOH}}$ and the volume of the PCL fibers $V_{\mathrm{PCL}}$ computed as the ratio between the initial scaffold mass before intrusion and $\left.\rho_{\mathrm{PCL}}\right)$. The second method was by gravimetry. Here the porosity was evaluated as $\varepsilon=1-\rho_{\mathrm{APP}} / \rho_{\mathrm{PCL}}$, where the apparent scaffold density $\rho_{\text {APP }}$ was measured as the mass to volume ratio on $20 \mathrm{~mm}$ dry disks. The last method sought to estimate the porosity $\varepsilon=V F$ as the average projected porosity deduced from the percent void fraction $V F$ as seen in top view SEM micrographs of the scaffolds. The percent $V F$ was determined simply by counting and summing the 
through thickness voids in a 2D SEM image. A Matlab ${ }^{\circledR}$ (MathWorks Inc.) script was written to properly convert grey scale images into a black a white format (with fibers and voids associated with black and white pixels, respectively) and to compute the void fraction (i.e. the fraction of white pixels) in an automated fashion. Unlike the previous two methods [19,27,36], the third is not a standard procedure, but was used to check how porosity measurements obtained by the previous two methods correlated with the projected porosity. Statistical comparison of the three methods was carried out on average estimates from five measurements using the paired $t$-test at the $10 \%$ significance level (i.e. significant difference for $P<0.1$ ).

\subsection{Pore size estimate}

The pore size estimate was pursued indirectly through approximate statistical models, similarly to earlier reports $[19,20]$. The elegant model of Eichhorn and Sampson [29] allows us to obtain the approximated distribution $p(r)$ of 3D pore radii $r$ associated with a unimodal fiber distribution:

$p(r)=\frac{n}{\varepsilon}\left(\frac{\Gamma(k, b n)}{\Gamma(k)}\right)^{n / \varepsilon-1} \frac{b^{k}}{\Gamma(k)} r^{k-1} \exp (-b r)$

where $\Gamma(k, b n)$ and $\Gamma(k)$ are the incomplete and complete gamma functions, respectively, $k$ is a constant parameter equal to $1.6, n$ is the equivalent number of layers and $b$ is an experimental parameter. The latter is defined as $b=2 k /\left\langle r_{2 \mathrm{D}}\right\rangle$ as a function of the average bi-dimensional pore diameter $\left\langle r_{2 \mathrm{D}}\right\rangle$ of one fiber layer, which in turn is related to $\varepsilon$ and to $\langle\omega\rangle$ by

$\left\langle r_{2 \mathrm{D}}\right\rangle \cong \frac{\sqrt{\pi}}{4}\left(\frac{\pi}{2 \ln (1 / \varepsilon)}-1\right)\langle\omega\rangle$

The distribution $p(r)$ is conceived as the superimposition of 2D layers, the number $n$ of which was assumed to be:

$n(\varepsilon, c) \cong \frac{c}{\ln (1 / \varepsilon)}$

which contains, besides $\varepsilon$, the coverage parameter:

$c(\beta,\langle\omega\rangle)=\frac{\text { total apparent scaffold volume }}{\text { volume of 1-monolayer of fibers }} \cong \frac{4}{\pi \rho_{\mathrm{PCL}}} \frac{\beta}{\langle\omega\rangle}$

computed from $\langle\omega\rangle$ and $\beta$, the latter being the average surface density, i.e. the ratio of the mass of the $20 \mathrm{~mm}$ disks to their surface area. Hence, the distribution $p(r)$ in Eq. (1) can be determined by feeding the set $\{\langle\omega\rangle, \varepsilon, \beta\}$ of three experimentally determined input parameters into Eqs. (2)-(4). Then the average pore radius $\langle r\rangle$, taken as a representative measure for the scaffold, is simply:

$\langle r\rangle=\int_{0}^{\infty} r p(r) d r$

A second model, proposed more recently by Sampson [29], was also used to obtain a refined estimate for $\langle r\rangle$. The second model differs from the former only in the equation below:

$\left\langle r_{2 \mathrm{D}}\right\rangle \cong \frac{\langle\omega\rangle}{\ln (1 / \varepsilon)}$

providing an alternative estimate of $\left\langle r_{2 \mathrm{D}}\right\rangle$ in place of Eq. (2). Both models were implemented in MAPLE (Maplesoft, Ont., Canada) for symbolic computation.

\subsection{Tensile tests}

Uniform static tensile tests were performed on $5 \times 20 \mathrm{~mm}^{2}$ sample strips cut from the thickness of large mats for all scaffold types. The thickness was still in the range $100-200 \mu \mathrm{m}$. A vertical single column loading frame ( $\mathrm{Z}$ 3, Thumler $\mathrm{GmbH}$, Germany) with a suitable load cell with a sensitivity of the order of $1 \mathrm{mN}$ was operated at a cross-head speed of $2 \mathrm{~mm} \mathrm{~min}^{-1}$ under ambient conditions. Sample mounting was performed gently by aligning each strip axially and lightly gripping it at the ends, while it remained relaxed so as to avoid pulling and pre-stressing of the material. Strain was calculated from cross-head displacement with respect to a gage length of $\sim 10 \mathrm{~mm}$, corresponding to the fully stretched configuration when load bearing began during the test. Stresses were computed by dividing the force by the apparent cross-sectional area $(A)$. Engineering stress vs. strain responses up to failure were collected to evaluate both selected elastic and inelastic properties, such as the Young's modulus $(E)$, the ultimate tensile stress (UTS) and the failure mode of the samples. Such estimates of $E$ and UTS based on the apparent cross-sectional area reflect the gross structural properties usually encountered in the literature and which are relevant to scaffold handling in clinical applications. However, to correlate these with PCL stiffness and strength at the fiber level, a (smaller) corrected cross-sectional area, deducting porosity and accounting only for those fibers oriented such as to bear the load (e.g. those aligned along the axis), should be used instead. While the fiber orientation issue is a non-trivial task [37] and was not undertaken, an area value $A^{*}$ corrected for the solid portion of the apparent cross-section was computed as $A^{*}=A \times S F$, based on the solid fraction $(S F)$ evaluated from SEM observations. Hence, upper bounds $E^{*}$ and $U T S^{*}$ of the PCL material were obtained, such that $E^{*}=E / S F$ and $U T S^{*}=U T S / S F$. The mechanical properties reported herein are averages for five test samples per material type.

\subsection{Biological experiments}

\subsubsection{Cell culture}

Mesenchymal stem cells represent a valid benchmark due to their multipotential stemness and the extensive related literature [14-16,19,22,33-35]. Our mTERT-MSCs were obtained by transfection of lineage negative, Sca- 1 positive stem cells $\left(\mathrm{Lin}^{\text {neg }} / \mathrm{Sca}-1^{\text {pos }}\right.$ MSC) from 6-week-old female C57/Bl mice femurs, as described elsewhere [38]. Sca- $1^{\text {pos }}$-enriched mTERT-MSCs were selected by two sets of magnetic cell sorting protocols (Miltenyi Biotec $\mathrm{GmbH}$, Bergisch Gladbach, Germany) and resuspended in Dulbecco's modified Eagle's medium (DMEM) (Cambrex Bio Science, Verviers, Belgium), supplemented with $10 \%$ fetal bovine serum (FBS), $1 \times$ Insulin-transferrin-sodium selenite (ITS; Sigma-Aldrich), 100 $\mathrm{IU} \mathrm{ml} l^{-1}$ penicillin and $100 \mu \mathrm{g} \mathrm{ml}^{-1}$ streptomycin (hereafter referred to as complete medium) in a humidified atmosphere at $37{ }^{\circ} \mathrm{C}$ and $5 \% \mathrm{CO}_{2}$. Cells in suspension were rounded and their size typically ranged around $20-30 \mu \mathrm{m}$. When attached the typical cell size range was $50-70 \mu \mathrm{m}$. mTERT-MSCs were seeded on relatively thin scaffold, limited to $100-200 \mu \mathrm{m}$ thickness (rather than millimeters as in other works, for example [19]), following literature indications for soft tissue applications $[9,39,40]$.

\subsubsection{Scaffold preparation and cell seeding}

Before cell seeding the scaffolds were placed in 24-well low attachment culture plates (Corning Inc., NY), sterilized under UV light for $15 \mathrm{~min}$ and equilibrated with complete medium overnight at $37{ }^{\circ} \mathrm{C}, 5 \% \mathrm{CO}_{2}$. The next day mTERT-MSCs were detached from the culture plates using trypsin/EDTA solution $[0.25 \%$ in phosphate-buffered saline (PBS)] and centrifugated for $5 \mathrm{~min}$ at $1000 \mathrm{rpm}$. The pellet was resuspended in complete medium and viable cells counted after trypan blue staining. Subsequently, the medium was removed from each well and $4 \times 10^{4}$ cells per scaffold were seeded in a small volume ( $50 \mu \mathrm{l}$ per scaffold) and allowed to attach for $1 \mathrm{~h}$ in a humidified atmosphere at $37^{\circ} \mathrm{C}, 5 \% \mathrm{CO}_{2}$. Thereafter, seeded scaffolds were transferred to new 24 -well plates and 
complete medium added to each well $(1 \mathrm{ml} /$ well). The medium was changed every other day.

\subsubsection{Cell morphology analysis}

The morphology of the cells was evaluated by hematoxylin and eosin staining according to the manufacturer's instructions (Bio-Optica, Milano, Italy). Briefly, 1 week after seeding the scaffolds were washed with fresh PBS, fixed for $30 \mathrm{~min}$ at $4{ }^{\circ} \mathrm{C}$ with $4 \%$ paraformaldehyde (PFA) and stained for 5 min with hematoxylin and eosin. For immunofluorescence, cells were washed in PBS, fixed in $4 \%$ PFA in PBS containing $\mathrm{CaCl}_{2}$ for $30 \mathrm{~min}$ at $4{ }^{\circ} \mathrm{C}$ and permeabilized with $0.1 \%$ Triton X-100. Cells were stained with tetrarhodamine-conjugated phalloidin (Invitrogen Corp., CA). Nuclei were counterstained with $4^{\prime}, 6^{\prime}$-diamidino-2-phenylindole (DAPI) (Sigma-Aldrich). The images were taken using a Leica DMRB microscope equipped with a digital camera (Leica Instruments, Heidelberg, Germany).

\subsubsection{Cell viability assay}

Cell viability within the scaffolds was assessed after 1, 3 and 7 days culture using the 3-(4,5-dimethylthiazol-2-yl)-2,5-diphenyltetrazolium bromide (MTT)-based colorimetric assay as per the manufacturer's instructions (Sigma-Aldrich, Concorezzo, Italy). Briefly, seeded scaffolds were transferred to new culture plates and fresh medium added in the presence of MTT solution. Four hours later formazan crystals were dissolved by adding MTT solvent. The values calculated are expressed as $\left(\mathrm{OD}_{570 \mathrm{~nm}}-\mathrm{OD}_{690 \mathrm{~nm}}\right)$, where OD is the optical density. At least eight OD measurements were taken for each scaffold and at each time point and mean values were calculated.

\subsubsection{Cell diffusion through thickness}

After 7 days culture the scaffolds were mounted in cryostat embedding medium (Killik, Bio-optica, Milano, Italy) at room temperature and cooled in a cryostat chamber. Scaffold samples were sliced parallel to the disk plane from the top surface through the entire thickness with an $8 \mu \mathrm{m}$ step size. Slicing was monitored to track the depth of each sliced section from the reference top surface. Slices were collected in a cryostat chamber on Fisher Super Frost Plus slides, dried at room temperature, washed once with PBS and stained with DAPI. The images were taken using the aforementioned Leica microscope with digital camera.

\subsection{6. mTERT-MSCs differentiation on fibrous scaffolds}

mTERT-MSCs grown on the scaffolds were cultured for 2 weeks in adipogenic medium (Cambrex Bio Science) or osteogenic induction medium containing DMEM (Cambrex Bio Science) with 10\% FBS, $10^{-8} \mathrm{M}$ dexamethasone, $10 \mathrm{mM} \beta$-glycerolphosphate, $50 \mu \mathrm{M}$ ascorbic acid (all Sigma-Aldrich) and antibiotics. To assess adipogenic differentiation seeded scaffolds were stained with AdipoRed for 10 min according to the manufacturer's instructions (Cambrex Bio Science) and visualized using fluorescence microscope. Nuclei were stained with DAPI. For osteogenesis cells induced to differentiate were stained with a $40 \mathrm{mM}$ solution of Alizarin Red S ( $\mathrm{pH} 4.1$ in distilled water) [41] (Sigma-Aldrich) for $20 \mathrm{~min}$ at room temperature. The presence of calcification deposits (bright red) was assessed by light microscopy. Non-induced cells and scaffolds without cells were used as negative controls.

\subsubsection{Statistical analysis}

The results are shown as means \pm standard deviation (SD) as derived by unpaired $t$-test. The values are considered significantly different when $P<0.05$. The number of replicated experiments performed is given as $n$.

\section{Results and discussion}

\subsection{Materials characterization}

\subsubsection{Morphology}

Fig. 2 shows representative SEM micrographs of top views of the four scaffolds corresponding to the process parameters listed in Table 1 . The controls in Fig. 2A-C exhibited typical unimodal distributions with $\langle\omega\rangle=0.3-5.2 \mu \mathrm{m}$. One can observe that the microscale fibers showed nanoscale roughness, which improved the biological performance. The novel MIX scaffold (Fig. 2D) showed a bimodal distribution with $\langle\omega\rangle=3.3 \cup 0.6 \mu \mathrm{m}$. For the latter material fine and homogeneous mingling between the two fiber populations is better seen in the cross-sectional view in Fig. 3. No composition gradient through the thickness could be noticed on the cross-sections, suggesting homogeneous electrospinning from the bottom to the top surface. This is a valuable result because homogeneity, although desirable, may be difficult to achieve due to the increasing electrostatic repulsion amongst the accumulating fibers as the scaffold thickness increased (even if that becomes reportedly problematic only for walls much thicker than ours, i.e. $>1 \mathrm{~mm}[15,19])$. From a processing standpoint, the mingling quality depended heavily upon the rotation speed of the stage carrying the target. Slower rates (e.g. 5-10 rpm) yielded layered scaffolds, as in Pham et al. [19], as the result of an excessive exposure time of the collector target to each syringe. This makes for an innovative fabrication in itself, potentially exploitable in a modular continuous flow production strategy (beyond the scope of the present article). By increasing the speed of the stage fiber separation could be prevented and a transition occurred towards homogeneous fiber mixing. The reported results refer to the optimum condition for our set-up of about $30 \mathrm{rpm}$. Above this limit the inertia of the spinning jet became an issue and no scaffold could form at excessive speeds (e.g. 80 Pham $100 \mathrm{rpm}$ ) as neither of the two electrospin jets was rapid enough to catch up and deposit onto the fast moving collector. In this respect, it was somewhat counter-intuitive to observe that the relative percentage of microfibers increased with speed between 30 and 60 rpm, suggesting that inertia affected the lighter nanofibers earlier than the bulkier microfibers. This effect was likely a complex compound effect of mass density, speed, electric charge density of the electrospin jet and deserves further investigation.

Fig. 4 shows the scaffold porosity for each sample, estimated as average $\varepsilon_{\%}$ value from liquid intrusion, gravimetry and percent $V F$. The three methods appeared to be in good agreement and multiple pair-wise statistical comparisons yielded no significant differences (i.e. $P>0.1$ ). The porosity appeared to decrease with $\langle\omega\rangle$ and the grand means from the three $\varepsilon \%$ estimates were about $86 \%, 88 \%$ and $93 \%$ for the unimodal control scaffolds, respectively, and $90 \%$ for the MIX, in agreement with the literature [19].

The representative pore sizes computed from the two models (arbitrarily using the liquid inclusion measures of $\varepsilon_{\%}$ as input) are reported in Table 2 for each scaffold material. Both models were applied to the three unimodal control scaffolds, but also, as a first approximation, to the bimodal MIX, considering just $\langle\omega\rangle=3.3 \mu \mathrm{m}$ and discarding the nanofibers. Regarding Model 1 [based on Eq. (2)], the values estimated for the unimodal scaffolds were smaller than in the literature [19] for similar $\langle\omega\rangle$. Such estimates were also significantly smaller than those from Model 2 [based on Eq. (6)], used here for the first time on electrospun scaffolds, which is supposedly more accurate [30]. In this respect, the larger values from Model 2 could actually mean an improvement over Model 1, which seemed to consistently underestimate the pore size when validated against experimental mercury porosimetry in the $\langle\omega\rangle$ range $4-10 \mu \mathrm{m}$ [19]. It is worth mentioning that mercury porosimetry could not be applied at and below $3 \mu \mathrm{m}$ due to the 

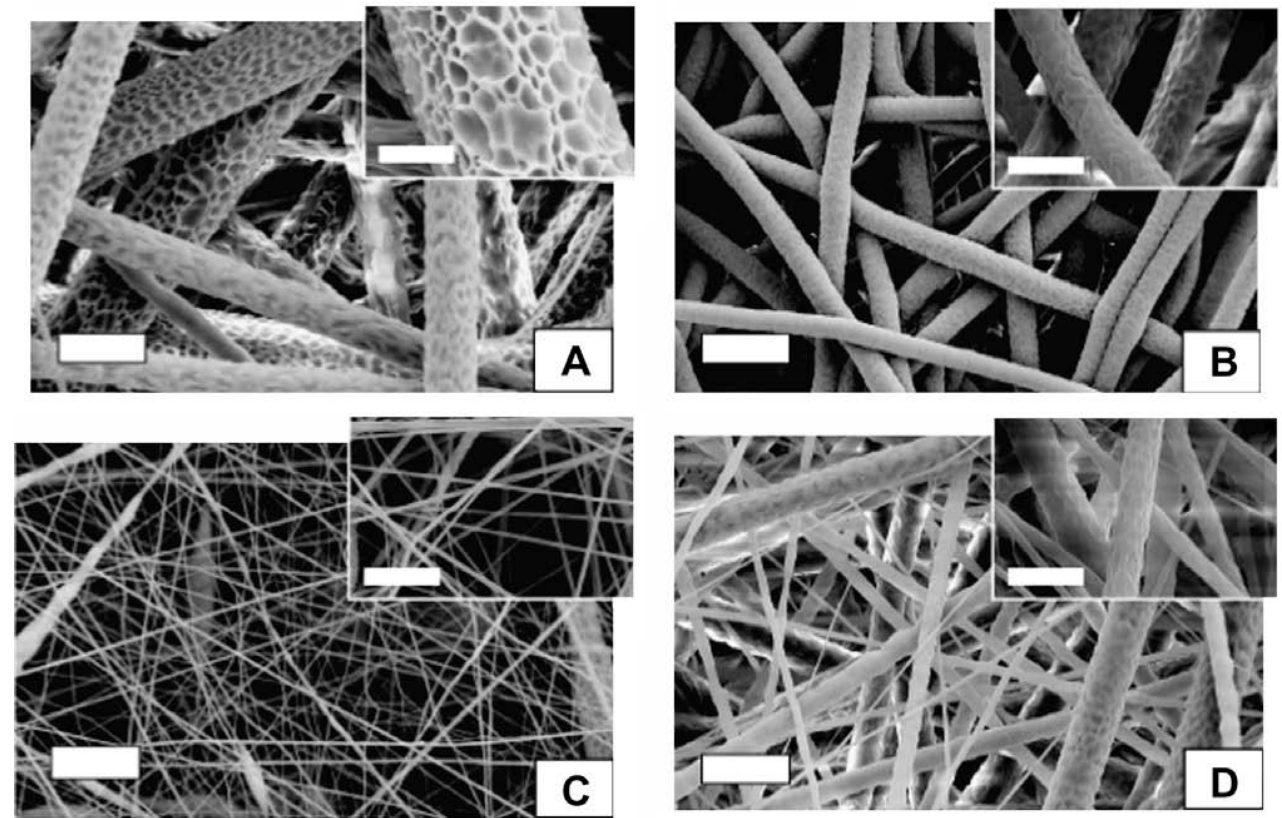

Fig. 2. FEG-SEM micrographs of electrospun fibers consisting of the four scaffold types tested. $\langle\omega\rangle=(\mathrm{A}) 5.2 \mu \mathrm{m}$; (B) $2.6 \mu \mathrm{m}$; (C) $0.3 \mu \mathrm{m}$; (D) $3.3 \cup 0.6 \mu \mathrm{m}$. The large pictures show micrographs at $5000 \times$ with a $10 \mu \mathrm{m}$ scale bar, whereas the insets refer to $20,000 \times$, with a $5 \mu \mathrm{m}$ scale bar.

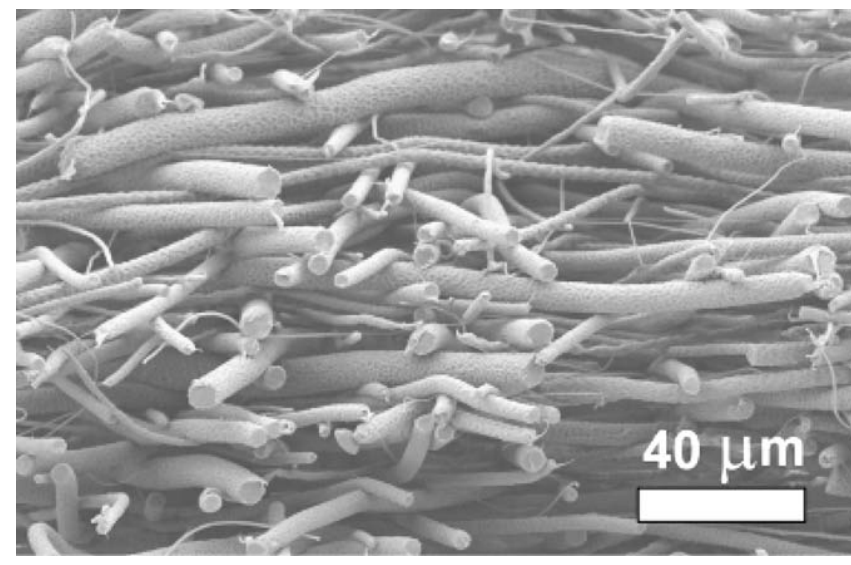

Fig. 3. FEG-SEM micrograph of a cross-section of the MIX scaffold showing both nano- and micro-fibers.

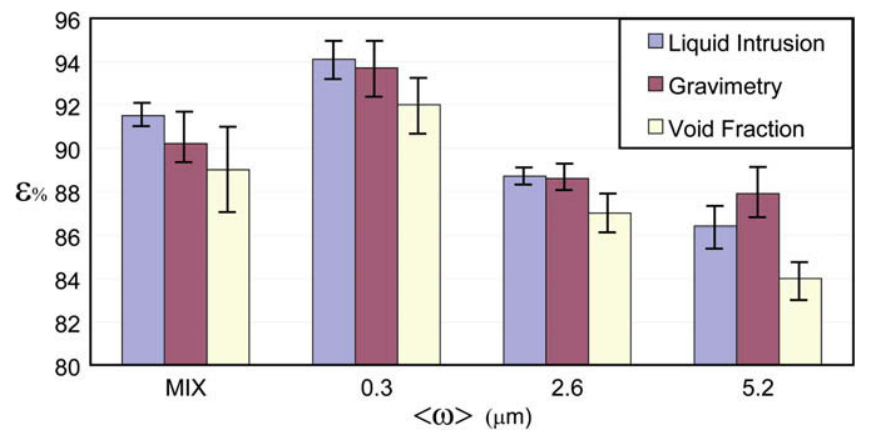

Fig. 4. Comparison of average measurements of $\varepsilon_{\%}$ by the three techniques reported in the figure, shown for each tested scaffold type.

pressure level, excessive for these materials. At present, although these models represent the state of the art, further validation experiments are required to positively establish their level of performance, both in relative and absolute terms.
Table 2

Estimates of average pore size of the tested scaffold types obtained from two statistical models (Section 2.4) with the morphological input parameters $p(r)$ and $\varepsilon_{\%}$

\begin{tabular}{lllll}
\hline Scaffold type & $\langle\omega\rangle(\mu \mathrm{m})$ & $\begin{array}{l}\text { Porosity } \varepsilon_{\%} \\
\text { (liquid intrusion) }\end{array}$ & \multicolumn{2}{l}{ Pore size $p(r)(\mu \mathrm{m})$} \\
\cline { 4 - 5 } & & & (Model 1) & $($ Model 2) \\
\hline Control 1 & 5.2 & 87 & 9.4 & 14.9 \\
Control 2 & 2.6 & 89 & 3.2 & 5.1 \\
Control 3 & 0.3 & 94 & 0.1 & 0.2 \\
MIX & $3.3 \cup 0.6$ & 92 & 5.6 & 8.5 \\
\hline
\end{tabular}

Pore size determination remains a controversial issue for electrospinning, starting from the same definition of pore size, which was formally ill-defined for electrospun materials. In reality, electrospun scaffolds consist of fiber networks with open porosity, but the above theoretical approach considers the distribution of conveniently - yet conventionally - defined virtual closed pores that best fit the interstices between fibers. Following a second line of thought, other authors have questioned the role of pore size and the dependence between $\langle r\rangle$ and $\langle\omega\rangle$ [21]. Based on nuclear magnetic resonance (NMR) experiments on unimodal PCL scaffolds, they obtained pore sizes of $\sim 56-69 \mu \mathrm{m}$ (i.e. one order of magnitude larger than ever found with the other approach) without a significant difference in pore size between $\langle\omega\rangle \sim 0.4$ and $1.5 \mu \mathrm{m}$ [21]. Hence, they cautioned that pore size would not be the critical morphological variable for cell viability and diffusion in their experiments with $10-15 \mu \mathrm{m}$ fibroblasts (although a possible bias could result from a scaffold thickness of just $\sim 50 \mu \mathrm{m}$, as admittedly pointed out). In the end, though, fibroblasts still seemed to show a marked tendency to grow preferentially as a monolayer on the surface rather than freely migrating inside. Furthermore, other reports on myofibroblasts indicated undisturbed migration only at $\langle\omega\rangle>12 \mu \mathrm{m}$ [20]. In conclusion, uncertainties hold for both viewpoints. Nonetheless, with respect to the 50-70 $\mu \mathrm{m}$ mTERT-MSCs seeded here, we could safely endorse the estimates in Table 2 and expect cell diffusion not to occur, neither in the controls nor in the MIX scaffold. We shall reconsider this expectation later, in the biological validation. 


\subsubsection{Mechanical properties}

The gross properties indicated that electrospun materials made of thicker fibers appeared to be stiffer and stronger. In fact, the stiffness increased with $\langle\omega\rangle$ of the microfibers both for the controls as well as the MIX samples. The $E$ and UTS for $\langle\omega\rangle=0.3 \mu \mathrm{m}$ confirmed that nanoscale fibers would have relatively poor mechanical properties by themselves, preventing their usage in practice as stand-alone scaffolds in clinical applications. This is also consistent with the larger porosity measured for that scaffold type. At the polymer level the corrected stiffness $E^{*}$ and strength UTS indicated that the PCL material experienced stress levels at least one order of magnitude larger. The MIX samples exhibited gross mechanical properties on a par with the control scaffold $(5.2 \mu \mathrm{m})$, but was superior in terms of UTS at the material level. Although the most notable difference between the MIX and the controls was perhaps the softening behavior (i.e. the stress response after UTS was reached) and the corresponding failure mode. Unimodal scaffolds showed a tendency to break apart as a bundle of parallel fibers (the load-bearing ones in the network), a Mode I crack, as depicted in Fig. 5A. The bimodal MIX failed as a multilayered composite by delamination, due to propagation of a Mode II crack with partition of the thickness into two parts, an upper stack sliding over a lower one, as shown in Fig. 5B. This is not surprising since a well-mingled bimodal scaffold (i.e. our MIX) can be considered a gradual evolution from an actual multilayered bimodal structure when the speed of rotation of the stage in Fig. 1B approached the optimal speed. In this view, if the organization of alternating pseudo-layers was retained in the MIX from the original multilayered composite (although no longer discernable to the eye), delamination failure would simply reflect the characteristic microstructural ordering. Thus, such a failure would initiate at the weaker interface between adjacent pseudo-layers of nano- and microfibers and proceed along the path of least resistance pattern along other weak interfaces by bridging across. Furthermore, the MIX failure was advantageously more ductile than the controls, which experienced a brittle rupture with a sharp crack surface extending over the entire sample width.

\subsection{Biological validation}

\subsubsection{Cell viability}

To investigate the effect of different fiber diameters on cell adhesion and viability, mTERT-MSCs were seeded onto all scaffolds. The MTT assay, a reliable standard test measuring cell metabolic activity as an indirect evaluation of viable cell number, was carried out on days 1 (adhesion), 3 and 7 of culture on the different PCL substrates. The results for the controls shown in Fig. 6 demonstrate that the maximum adhesion rate after 1 day culture was obtained with mTERT-MSCs seeded on $2.6 \mu \mathrm{m}$ fibers, as compared with 0.3 and $5.2 \mu \mathrm{m}$. However, $5.2 \mu \mathrm{m}$ scaffolds eventually recovered their biological performance and outperformed the $2.6 \mu \mathrm{m}$ in terms of cell viability after 7 days culture. Nanoscale fibers offered comparatively significantly lower adhesion and viability rates. Interestingly, when combined with $3.3 \mu \mathrm{m}$ fibers in the MIX scaffold nanofibers seemed to act in a synergistic way to enhance cell survival within the scaffold. In fact, the MIX scaffold performed similarly to the $2.6 \mu \mathrm{m}$ scaffold in terms of adhesion and surpassed the $5.2 \mu \mathrm{m}$ control at 7 days. These results indicate that the MIX scaffold had the best overall biological performance, confirming that cell attachment and survival within the scaffolds are strongly influenced by the microfiber diameter and that nanoscale fibers can substantially add to the performance.

\subsubsection{Cell diffusion: cell morphology and migration mechanisms}

The morphology of the mTERT-MSCs after seeding provides a wealth of information useful to understanding the relationship between scaffold microstructure and cell viability and motility. Typical histological staining (hematoxylin and eosin) was used to assess cell morphology on the scaffolds on day 7. The mTERT-MSCs were able to functionally adhere to all scaffolds, as indicated by the elongated morphology typical of healthy cells shown by the low magnification images in Fig. 7. However, important differences were noticed amongst scaffolds. On the two microscale controls (i.e. the 5.2 and $2.6 \mu \mathrm{m}$ scaffolds) the cells exhibited an evident tendency to be confined to a single fiber and aligned along it, likely because of the impossibility of bridging across microfibers that are far

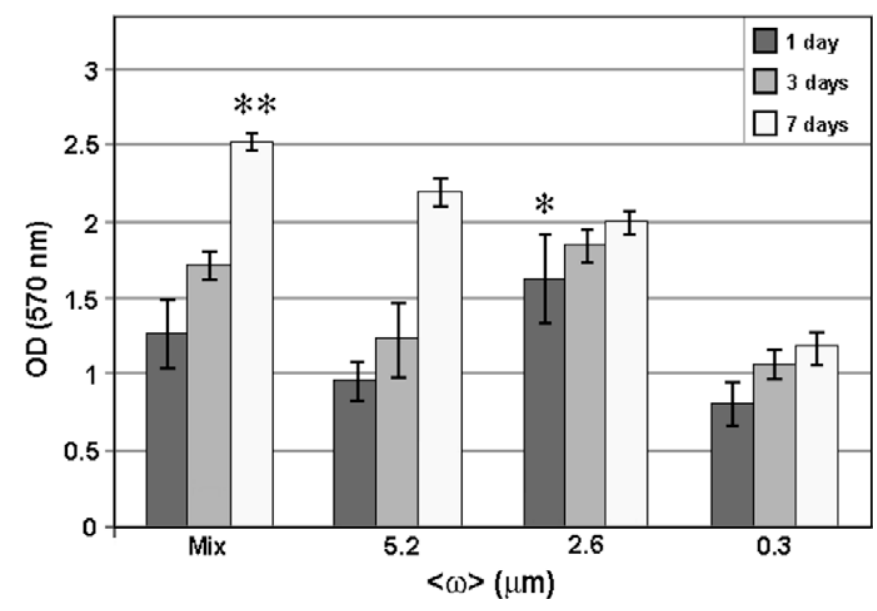

Fig. 6. mTERT-MSC adhesion to and viability on PCL scaffolds with different fiber diameters as determined by MTT assay. Data are represented as means $\pm \operatorname{SD}(n=8)$. $P<0.05$ for mTERT-MSC adhesion (1 day) on $2.6 \mu \mathrm{m}$ fibers, compared with 0.3 and $5.2 \mu \mathrm{m} . \quad \stackrel{* *}{P}<0.05$ for mTERT-MSC viability after 7 days culture on MIX scaffolds, as compared with all controls.

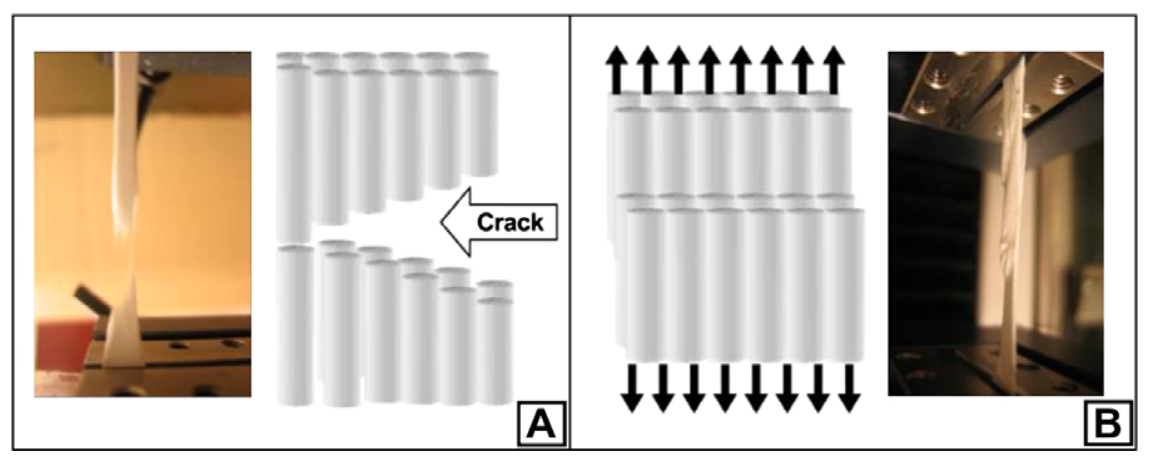

Fig. 5. Schematics of observed failure modes and actual pictures. Mode I crack typical of (A) fiber bundles and (B) delamination. 
apart. As expected, this effect was more evident on $5.2 \mu \mathrm{m}$ fibers (insets in Fig. 7), which is consistent with the viability data from the MTT assay. However, that did not inhibit cell motility and mTERTMSCs infiltrated into both scaffolds. On the other hand, the opposite situation was encountered for the $0.3 \mu \mathrm{m}$ scaffold. The mTERT-MSCs appeared to grow randomly on the nanofibrous surface (incapable of aligning in any way) and were unable to migrate inside the scaffold through the very small pores. Finally, a hybrid scenario occurred in the MIX scaffold. The mTERT-MSCs seemed to settle and align on the microfibers (as in the microscale controls) but also used the nanoweb of the second fiber population to bridge between neighboring microfibers. Such a synergistic mechanism of cell interaction with nano- and microfibers, which is not entirely new, as recalled in the Introduction (i.e. similar observations have been reported for bimodal scaffolds formed of microfibers two orders of magnitude larger than ours $[16,18])$, improved colonization of the inner layers of the scaffolds. Fig. 8 features immunofluorescence micrographs of rodhamine-phalloidin stained (red fluorescence) mTERT-MSCs with nuclei counterstained with DAPI (blue fluorescence). The mTERT-MSCs are clearly attached to both microfibers and nanofibers in the MIX scaffold by two types of adhesion points, as highlighted in the caption. These results suggest that in a MIX scaffold, if the microfibers produce pores large enough to accommodate cells the nanofibers can fundamentally promote cell migration and should be regarded as a design variable, on a par with pore size, to optimize the microstructure for cell motility.

A second study focusing on the MIX scaffold was conducted to characterize the actual colonization of seeded cells through the scaffold wall. After 7 days culture seeded scaffolds were sliced from the top (reference) to the bottom surface every $8 \mu \mathrm{m}$ to analyze transverse sections at different depths and to determine whether mTERT-MSCs were able to colonize the inside of the scaffold after an initially homogeneous seeding. All controls, as predicted from the results of the pore size analysis, yielded a negative outcome, with no cells found in the scaffold (sections not shown). In contrast, MIX scaffolds were found to be entirely colonized by cells (stained blue with DAPI), as demonstrated by the sections in Fig. 9, representative of different depths and displayed in order from innermost (at $192 \mu \mathrm{m}$, Fig. 9A) to outermost (at $64 \mu \mathrm{m}$, Fig. 9D), at the top surface. Similar cell densities confirmed free migration throughout the whole scaffold domain, with no density gradient across the thickness. This result contradicts the prediction based on the theoretical estimate of the average pore size (Table 2). It is non-trivial to pinpoint why the applied models work for the controls but are inaccurate for the specific bimodal architecture of the MIX. A refined formulation accounting for multimodal input is probably required. We note, for example, that current predictions considered only the microfiber diameter $\omega$ (i.e. neglecting the nanofibers), whereas the other experimental inputs (i.e. $p(r)$ and $\varepsilon_{\%}$ ) relate to both fiber types. Actually, nanofibers may have a different functional value for motility, most likely because cells need to use less force to bend them and move through them [21]. Although counter-intuitive, these findings open up the possibility that the MIX scaffold has a "loosened" microstructure resulting from substitutional nanofibers that endow it with effectively larger pores without impairing the mechanical strength (Table 3). Alternatively, we can envision other likely causes able to alter the microstructure in a similar manner. For example, MIX is the outcome of a truly dynamic process, where the polymer jet from each syringe is subject to periodic variations in the electric field and, hence, is forced to follow a non-stationary trajectory dependent on the speed of rotation of the target when the geometry of the set-up is fixed. Periodic variation in the distance between the collector target and needle tip can also contribute to non-stationary motion of the polarized polymer jet and may perhaps introduce in the scaffold (and in individual fibers) some residual stresses that can modify or pre-strain the microstructure in fundamental ways. In the future we plan to check this hypothesis on our materials via nano- and microindentation experiments, which are applicable for this purpose [42].

\subsubsection{Differentiation ability of mTERT-MSCs on PCL scaffolds}

To rule out the possibility that 3D PCL scaffolds could interfere with mTERT-MSCs plasticity, standard adipogenic and osteogenic
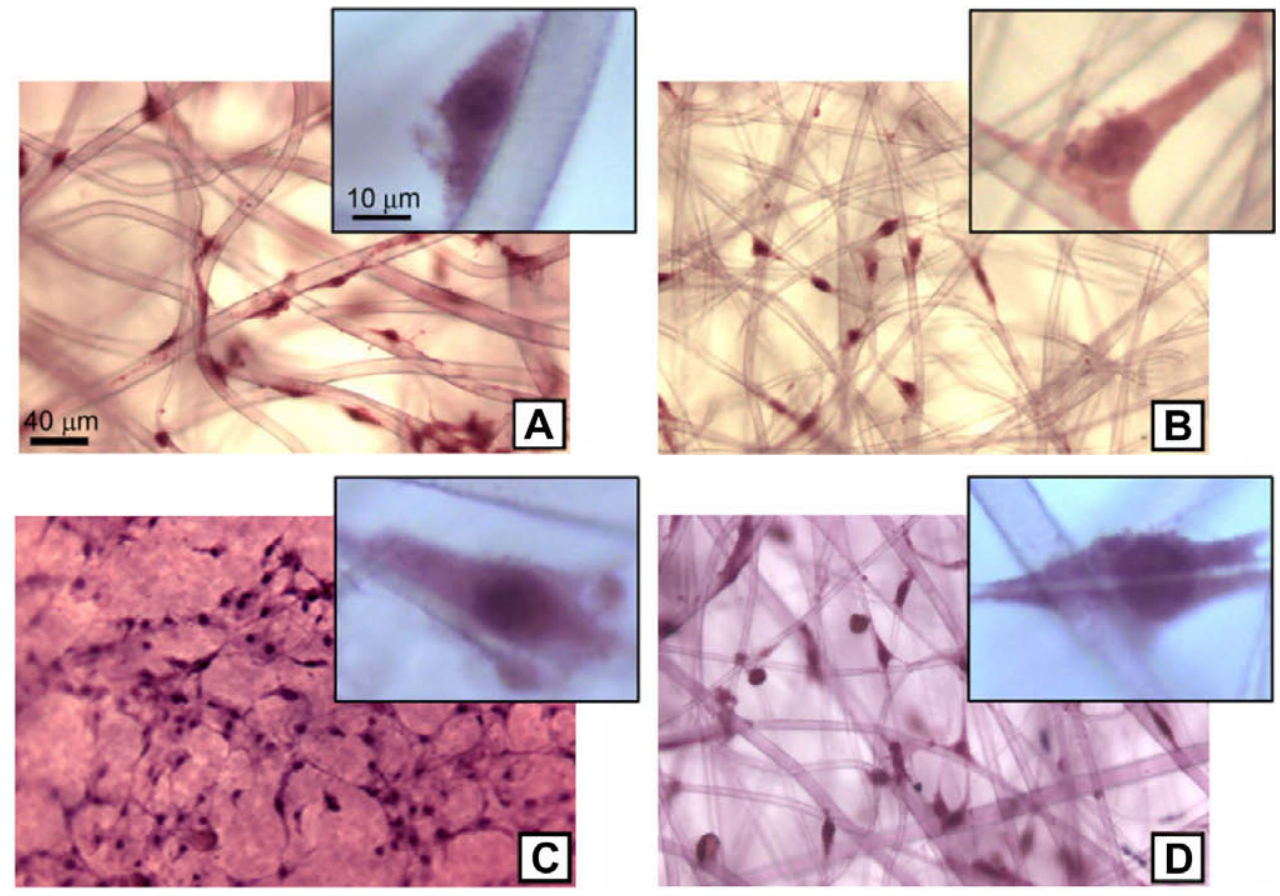

Fig. 7. Hematoxylin and eosin staining of mTERT-MSC grown on PCL scaffolds with $\langle\omega\rangle=(A) 5.2 \mu \mathrm{m}$, (B) $2.6 \mu \mathrm{m}$, (C) $0.3 \mu \mathrm{m}$ and (D) $3.3 \cup 0.6 \mu \mathrm{m}$. Higher magnification insets show cell interactions with the fibers. The scale bar in (A) applies to all. 

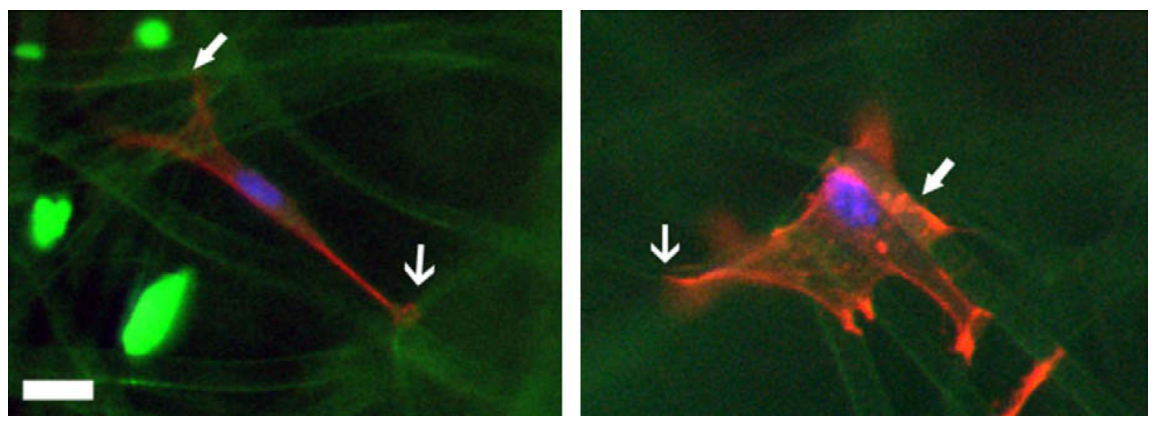

Fig. 8. Immunofluorescence micrographs of rodhamine-phalloidin stained (red fluorescence) mTERT-MSC on the MIX scaffold. The images show interaction (e.g. adhesion points) between cells and microfibers (wide arrows) or nanofibers (narrow arrows). Nuclei are counterstained with DAPI (blue fluorescence). Scale bar $5 \mu \mathrm{m}$ for both images.
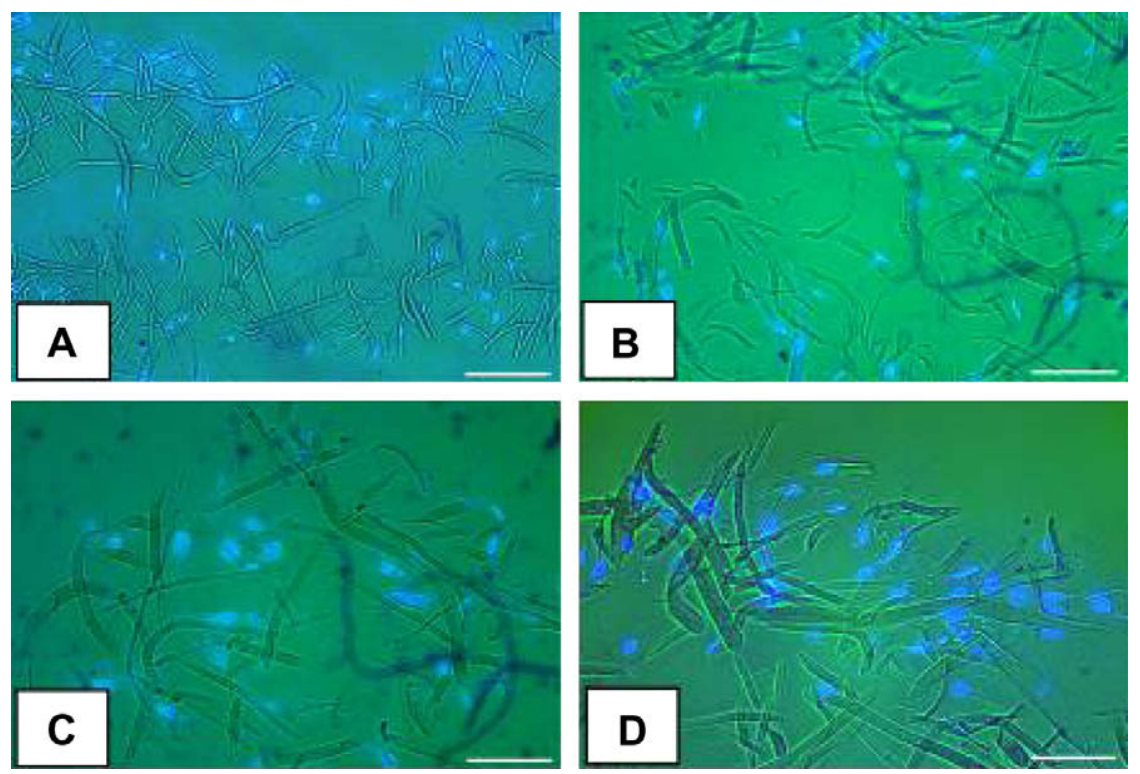

Fig. 9. mTERT-MSC (stained with DAPI) as grown after 7 days culture on MIX PCL scaffolds with $\langle\omega\rangle=3.3 \cup 0.6 \mu \mathrm{m}$. Sectioning depths from the reference surface are (A) $192 \mu \mathrm{m}$, (B) $128 \mu \mathrm{m}$, (C) $96 \mu \mathrm{m}$ and (D) $64 \mu \mathrm{m}$. (A) Scale bar $=100 \mu \mathrm{m}$; (B-D) scale bars $=50 \mu \mathrm{m}$. (Negative controls are shown in the supplementary online information.)

Table 3

Summary of mechanical properties for each scaffold type.

\begin{tabular}{llllll}
\hline Scaffold type & $\begin{array}{l}\text { Gross } E \\
(\mathrm{MPa})\end{array}$ & $\begin{array}{l}\text { Material } \\
E^{*}(\mathrm{MPa})\end{array}$ & $\begin{array}{l}\text { Gross UTS } \\
(\mathrm{kPa})\end{array}$ & $\begin{array}{l}\text { Material } \\
\text { UTS }^{*}(\mathrm{kPa})\end{array}$ & Failure mode \\
\hline Control 1 & 4.5 & 31.2 & 100 & 695 & Mode I crack \\
Control 2 & 3.0 & 24.1 & 72 & 580 & Mode I crack \\
Control 3 & 0.5 & 7.2 & 11 & 160 & Mode I crack \\
MIX & 4.0 & 40.0 & 92 & 920 & Delamination \\
\hline
\end{tabular}

differentiation tests were performed. Cells grown on the scaffolds were challenged with induction media and the occurrence of either adipogenic or osteogenic differentiation assessed as described in Materials and methods. In particular, intracellular lipid vacuoles inside the cells appeared after adipogenic stimulation (Fig. 10, upper panel). Furthermore, Alizarin Red S-positive mineralization deposits were detectable after 14 days induction by an appropriate medium, indicating osteoblast differentiation (Fig. 10, lower panel), but not in cultures untreated with osteogenic medium. No aspecific staining was observed in control cultures (data not shown). Lastly, it should be pointed out that Alizarin Red S may be insufficient to rule out the occurrence of dystrophic mineralization and SEM analysis of ECM should be carried out in the future for this purpose $[43,44]$. Our results suggest that mTERT-MSCs differentiation occurred on all substrates, indicating that none of the scaffolds affected the multilineage potential of mTERT-MSCs.

\section{Conclusions}

The multimodal MIX scaffold examined here offers substantial improvements over conventional unimodal scaffolds, in terms of both mechanical and biological performance. From a material point of view, the novel scaffold exhibited superior stiffness and strength in comparison with conventional scaffolds in the same fiber range. Remarkably, it simultaneously achieved a higher porosity and larger pores, as proved by the presence of MTERT-MSCs inside the MIX scaffold but not in the controls. However, besides pore size, mTERT-MSCs colonization of the MIX scaffold was also an effect of another concurrent factor, represented by "better cell motility" through the nanoscale fibers. Immunofluorescence indeed confirmed that nanofibers properly inserted in the primary network of microfibers crucially enhanced cell-scaffold interactions at the microstructural level by providing mTERT-MSCs with an additional means to efficiently bridge between microfibers, which ultimately boosts the biological performance in terms of motility and viability. These findings are somewhat counter-intuitive with respect to observations and models found in the literature. In particular, the current porosity models derived for unimodal scaffolds do not appear to be accurate and further research is needed to extend them to the multimodal case.

This innovative processing technique adds one more possibility to tailoring electrospun scaffolds in an even broader manner. With 


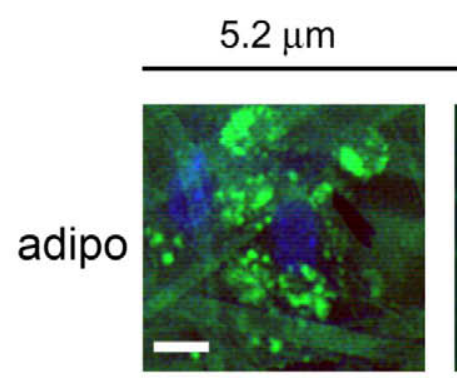

$2.6 \mu \mathrm{m}$

$0.3 \mu \mathrm{m}$ $3.3 \cup 0.6 \mu \mathrm{m}$
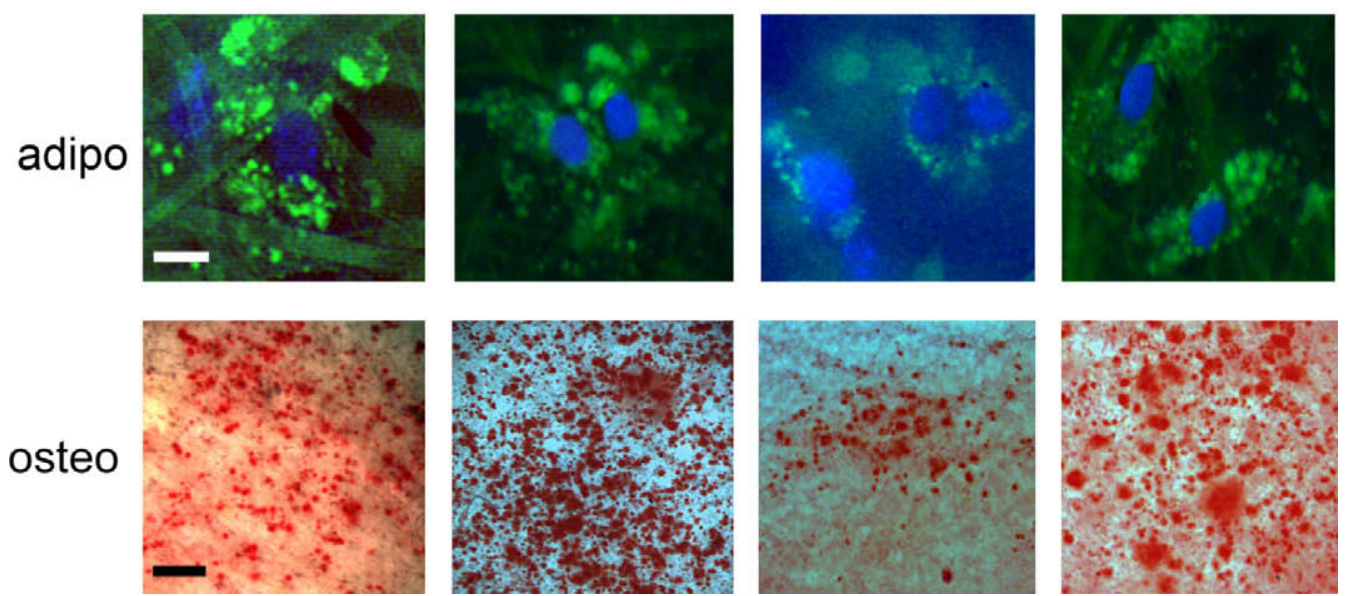

Fig. 10. Multilineage differentiation of the mTERT-MSC line was achieved on all PCL scaffolds tested at all fiber diameters. Adipogenic differentiation (upper panel, scale bar $=10 \mu \mathrm{m}$ ) was assessed by AdipoRed staining to detect the occurrence of lipid droplets (green), with nuclei (blue) counterstained with DAPI. Osteogenic differentiation (lower panel, scale bar $=300 \mu \mathrm{m}$ ) was ascertained by Alizarin Red S staining for calcium mineralization, revealing the typical presence of multiple red foci. (Negative controls are shown in the supplementary online information.)

a multimodal fiber distribution that can in principle be tuned at will, the controllability of the scaffold microstructure can be significantly improved, raising the chances of meeting the engineering requirements imposed by a desired tissue application in terms of multiscale architecture and pore structure. Compounding nanoand microfibers in one 3D multimodal scaffold should in principle allow different cell types to coexist, as sought in the cell therapy of complex tissues. Scalability and modularity are also appealing advantages from an industrial perspective in the long run.

\section{Acknowledgements}

A.R. and the other authors acknowledge William Sampson for his gracious support with the implementation of the pore size model and for insightful discussions.

\section{Appendix A. Supplementary data}

Supplementary data associated with this article can be found, in the online version, at doi:10.1016/j.actbio.2009.10.051.

\section{References}

[1] Langer R, Vacanti JP. Tissue engineering. Science 1993;260:920-6.

[2] Cao Y, Vacanti JP, Paige KT, Upton J, Vacanti CA. Transplantation of chondrocytes utilising a polymer-cell construct to produce tissue engineered cartilage in the shape of a human ear Plast Reconstruct Surg 1997; 100:297-302.

[3] Petite H, Viateau V, Bensaïd W, Meunier A, de Pollak C, Bourguignon M, et al. Tissue-engineered bone regeneration. Nat Biotechnol 2000;18:959-63.

[4] Nishida K, Yamato M, Hayashida Y, Watanabe K, Yamamoto K, Adachi E, et al. Corneal reconstruction with tissue-engineered cell sheets composed of autologous oral mucosal epithelium. N Eng J Med 2004;351:1187-96.

[5] Banta MN, Kirsner RS. Modulating diseased skin with tissue engineering: actinic purpura treated with Apligraf ${ }^{\circledR}$. Dermatol Surg 2002;28:1103-6.

[6] Stevens MM, George JH. Exploring and engineering the cell surface interface. Science 2005;310:1135-8

[7] Traversa E, Mecheri B, Mandoli C, Soliman S, Rinaldi A, Licoccia A, et al. Tuning hierarchical architecture of 3D polymeric scaffolds for cardiac tissue engineering. J Exp Nanosci 2008;3(2):97-110.

[8] Engler AJ, Sen S, Sweeney HL, Discher DE. Matrix elasticity directs stem cell lineage specification. Cell 2006;126:677-89.

[9] Forte G, Carotenuto F, Pagliari F, Pagliari S, Cossa P, Fiaccavento R, et al. Criticality of the biological and physical stimuli array inducing resident cardiac stem cell determination. Stem Cells 2008;26:2093-103.

[10] Subbiah T, Bhat GS, Tock RW, Pararneswaran S, Ramkumar SS. Electrospinning of nanofibers. J Appl Polym Sci 2005;96:557-69.
[11] Sill TJ, von Recum HA. Electrospinning: applications in drug delivery and tissue engineering. Biomaterials 2008;29:1989-2006

[12] Pham PQ Sharma U, Mikos AG. Electrospinning of polymeric nanofibers for tissue engineering application: a review. Tissue Eng A 2006;12(5):1197-211.

[13] Li WJ, Mauck RL, Tuan RS. Electrospun nanofibrous scaffolds: production, characterization, and applications for tissue engineering and drug delivery. J Biomed Nanotechnol 2005;1:259-75.

[14] Yoshimoto H, Shin YM, Terai H, Vacanti JP. A biodegradable nanofiber scaffold by electrospinning and its potential for bone tissue engineering. Biomaterials 2003;24:2077-82.

[15] Yang F, Murugan R, Wang S, Ramakrishna S. Electrospinning of nano/micro scale poly(L-lactic acid) aligned fibers and their potential in neural tissue engineering. Biomaterials 2005;26:2603-10.

[16] Tuzlakoglu K, Bolgen N, Salgado AJ, Gomes ME, Piskin E, Reis RL. Nano- and microfiber combined scaffolds: a new architecture for bone tissue engineering. J Mater Sci Mater Med 2005;16:1099-104.

[17] Santos MI, Tuzlakoglu K, Fuchs S, Gomes ME, Peters K, Unger RE, et al. Endothelial cell colonization and angiogenic potential of combined nano- and microfibrous scaffolds for bone tissue engineering. Biomaterials 2008;29:4306-13.

[18] Badami AS, Kreke MR, Thompson MS, Riffle JS, Goldstein AS. Effects of fiber diameter on spreading, proliferation, and differentiation of osteoblastic cells on electrospun poly(lactic acid) substrates. Biomaterials 2006;27:596-606.

[19] Pham Q, Sharma U, Mikos AG. Electrospun poly( $\varepsilon$-caprolactone) microfiber and multilayer nanofiber/microfiber scaffolds: characterization of scaffolds and measurement of cellular infiltration. Biomacromolecules 2006; 7:2796-805.

[20] Balguid A, Mol A, van Marion M, Bank RA, Bouten CVC, Baaijens FPT. Tailoring fiber diameter in electrospun poly( $\varepsilon$-caprolactone) scaffolds for optimal cellular infiltration in cardiovascular tissue engineering. Tissue Eng A 2008; $14: 1-8$

[21] Chen M, Patra PK, Warner SB, Bhowmick S. Role of fiber diameter in adhesion and proliferation of $\mathrm{NIH} 3 \mathrm{~T} 3$ fibroblast on electrospun polycaprolactone scaffolds. Tissue Eng A 2007;13(3):579-87.

[22] Li WJ, Tuli R, Huang X, Laquerriere P, Tuan RS. Multilineage differentiation of human mesenchymal stem cells in a three-dimensional nanofibrous scaffold. Biomaterials 2005;26:5158-66.

[23] Christopherson GT, Song $H$, Mao $H$. The influence of fiber diameter of electrospun substrates on neural stem cell differentiation and proliferation. Biomaterials 2009;30:556-64.

[24] Salerno A, Guarnieri D, Iannone M, Zeppetelli S, Di Maio E, Iannace S, et al. Engineered mu-bimodal poly(epsilon-caprolactone) porous scaffold for enhanced hMSC colonization and proliferation. Acta Biomater 2009:5(4):1082-93.

[25] Levy-Mishali M, Zoldan J, Levenberg S. Effect of scaffold stiffness on myoblast differentiation. Tissue Eng A 2009;15(4):935-44.

[26] Mandoli C, Mecheri B, Forte G, Pagliari F, Pagliari S, Carotenuto F, et al. Thick soft tissue reconstruction on highly perfusive biodegradable scaffolds. Macromol Biosci 2009. doi:10.1002/mabi.200900323.

[27] Hu Y, Grainger DW, Winn SR, Hollinger JO. Fabrication of poly(a-hydroxy acid) foam scaffolds using multiple solvent systems. J Biomed Mater Res 2001;59:563-72 
[28] Yang SF, Leong KF, Du ZH, Chua CK. The design of scaffolds for use in tissue engineering. Part I. Traditional factors. Tissue Eng A 2001;7:679-89.

[29] Eichhorn SJ, Sampson WW. Statistical geometry of pores and statistics of porous nanofibrous assemblies. J R Soc Interface 2005;2:309-18.

[30] Sampson WW. Modeling stochastic fibrous materials with Mathematica ${ }^{\circledR}$. In: Engineering materials and processes, XII. Berlin: Springer; 2009.

[31] Van Lieshout MI, Vaz CM, Rutten MC, Peters GW, Baaijens FP. Electrospinning versus knitting: two scaffolds for tissue engineering of the aortic valve. J Biomater Sci Polym 2006;17:77-89.

[32] Chen Q, Bismarck A, Hansen U, Junaid S, Tran MQ, Harding SE, et al. Characterisation of a soft elastomer poly(glycerol sebacate) designed to match the mechanical properties of myocardial tissue. Biomaterials 2008;29:47-57.

[33] Caplan AI. Adult mesenchymal stem cells for tissue engineering versus regenerative medicine. J Cell Physiol 2007;213:341-7.

[34] Yoneno K, Ohno S, Tanimoto K, Honda K, Tanaka N, Doi T, et al. Multidifferentiation potential of mesenchymal stem cells in threedimensional collagen gel cultures. J Biomed Mater Res A 2005;75(3):733-41.

[35] Srouji S, Kizhner T, Suss-Tobi E, Livne E, Zussman E. 3-D nanofibrous electrospun multilayered construct is an alternative ECM mimicking scaffold. J Mater Sci Mater Med 2008;19:1249-55.

[36] Moroni L, Licht R, de Boer J, de Wijn JR, van Blitterswijk CA. Fiber diameter and texture of electrospun PEOT/PBT scaffolds influence human mesenchymal stem cell proliferation and morphology, and the release of incorporated compounds. Biomaterials 2006;27:4911-22.
[37] Courtney T, Sacks MS, Stankus J, Guan J, Wagner WR. Design and analysis of tissue engineering scaffolds that mimic soft tissue mechanical anisotropy. Biomaterials 2006;27:3631-8.

[38] Forte G, Franzese O, Pagliari S, Pagliari F, Di Francesco A, Cossa P, et al. Interfacing Sca-1pos mesenchymal stem cells with biocompatible scaffolds with different chemical composition and geometry. J Biomed Biotechnol 2009;2009:910610.

[39] Caspi O, Lesman A, Basevitch Y, Gepstein A, Arbel G, Huber I, et al. Stem cells tissue engineering of vascularized cardiac muscle from human embryonic. Circ Res 2007;100:263-72.

[40] Bursac N, Papadaki M, Cohen RJ, Schoen FJ, Eisenberg SR, Carrier R, et al. Cardiac muscle tissue engineering: toward an in vitro model for electrophysiological studies. Am J Physiol 1999;277(2 Pt. 2):H433-44.

[41] Gregory CA, Gunn WG, Peister A, Prockop DJ. An Alizarin red-based assay of mineralization by adherent cells in culture: comparison with cetylpyridinium chloride extraction. Anal Biochem 2004;329(1):77-84.

[42] Rinaldi A, Peralta P, Friesen C, Chawla N, Traversa E, Sieradzki K. Localized compression and shear tests on nanotargets with a Berkovich tip and a novel multifunctional tip. J Mater Res 2009;24(3):768-75.

[43] Bonewald LF, Harris SE, Rosser J, Dallas MR, Dallas SL, Camacho NP, et al. Von Kossa staining alone is not sufficient to confirm that mineralization in vitro represents bone formation. Calcif Tissue Int 2003;72:537-47.

[44] Karp JM, Ferreira LS, Khademhosseini A, Kwon AH, Yeh J, Langer RS. Cultivation of human embryonic stem cells without the embryoid body step enhances osteogenesis in vitro. Stem Cells 2006;24:835-43. 